\title{
Conservative treatment of aseptic necrosis of the femoral head in adults (literature review)
}

\author{
V.V. Lobashov, A.V. Zainutdinov, I.F. Akhtyamov
}

Kazan State Medical University, Kazan, Russian Federation

\begin{abstract}
Introduction Aseptic necrosis of the femoral head (ANFH) is one of the orthopedic diseases affecting the socially active population. This fact determines the keen interest of researchers in this nosological type. At present, there is no consensus on the ANFH etiology and pathogenesis, what complicates the choice of treatment tactics. The efficiency of conservative treatment, despite the existence of several options, is currently controversial. The reasons for this remain the ambiguity of research results associated with a low level of evidence, heterogeneity of patients samples, different approaches to studying the efficacy of various treatment methods. The aim of this work is to analyze studies of a high level of evidence on the effectiveness of the use of conservative methods in the treatment of ANFH. Material and methods The study reviews the studies published between 2010 and 2017 (61) available in various information systems (PubMed, eLibrary.ru, etc.). Results The data from the studies of evidence levels I and II showed the ineffectiveness of using the method of joint unloading and lipid-lowering agents in the treatment of patients with ANFH. The use of anticoagulants in idiopathic (primary) ANFH in the pre-collapse stage was justified. The effectiveness of biophysical methods (hyperbaric oxygenation, extracorporeal shockwave therapy and pulsed electromagnetic fields) and cell therapy was confirmed in terms of relieving pain, improving the functional state of the joint and metabolic processes in it at the early stage of the disease. The efficacy of the drug iloprost in eliminating pain and edema in patients with ANFH at an early stage was proven. The opinions of researchers about the effect of bisphosphonates on the results of treatment in patients with ANFH are controversial. Conclusion There is insufficient evidence to prove the effectiveness of any of the conservative treatment methods, but there are studies proving their partial effectiveness. Complete recovery of the joint, as a rule, does not occur, but in most cases it is possible to prevent joint damage, reduce destructive processes in the femoral head and pain, and maintain the functional state of the muscles.

Keywords: avascular necrosis, femoral head, conservative treatment
\end{abstract}

Aseptic necrosis of the femoral head (ANFH) is a multifactorial degenerative disease of the skeletal system, leading to dysfunction of the hip joint due to impaired blood flow and necrosis of bone marrow elements in this anatomical region. ANFH usually develops at the age of 35-55 years [1]. For a long time, ANFH was referred to as "Perthes disease". Scientists mistakenly considered the etiology, pathogenesis and treatment of this nosological type as common for adults and children. Later, many researchers became aware that the disease in children develops milder and, due to better blood supply and greater reparative capabilities, the bone tissue may finally restore, and even with the preservation of the femoral head structure, what, as a rule, does not occur in adults [2].

In the United States, 10,000 to 50,000 new cases of avascular necrosis of the femoral head have been diagnosed each year [3, 4]. This pathology mainly affects young people, and only $20 \%$ of patients are at the age of over 50 years [5]. Men are susceptible to this disease three times more than women. Half of the cases have bilateral involvement [3,5]. ANFH frequently results in disability and dysfunction of the hip joint. If not treated, coxarthrosis develops in $30-50 \%$ of cases on average. As a consequence, about 5 to $18 \%$ of all hip arthroplasty operations are performed for ANFH $[3,6]$.

Depending on the causes, primary or secondary ANFH is conventionally distinguished. If the causes of ANFH are unknown, it is described as idiopathic (primary) in 40-50\% of cases [7, 8]. Among the causes of secondary ANFH, approximately $40 \%$ of cases are associated with the use of glucocorticosteroids [7]. There are rare cases of the disease caused by ionizing radiation, hyperlipidemia, sickle cell anemia, fat embolism, and some others.

There are several theories of ANFH pathogenesis: vascular, genetic, impaired reparative bone regeneration, and others. According to the vascular theory, the root cause and the main predisposing factor of aseptic necrosis of the femoral head is arterial occlusion which may result from fat embolism or thrombosis leading to ischemia of bone tissue and its subsequent necrosis. External compression of capillaries is also possible and results from underdevelopment of hip joint vessels. Reparative disorders of bone function are associated with an impaired process of bone formation.

Histological studies in the initial phase of the disease detected signs of osteoclastic destruction of bone trabeculae. 
In the phase of necrosis, bone resorption developed intensively. In the phase of restructuring, chondroplastic formation of bone trabeculae took place [1]. Risk factors often include inherited rs662 polymorphism in the PON1 gene [9] which is associated with hyperlipidemia, and as an increase in the PAI-1 level [10], a mutation in methylenetetrahydrofolate reductase [11, 12].

Not a single separate factor may explain the ANFH pathogenesis, but each of them may be present, which determines the multifactorial nature of the pathology.

Unclear etiology and pathogenesis makes the choice of therapy difficult. This explains the purpose of our work aimed at an analytical review of the literature highlighting the results of the studies with high level of evidence on the effectiveness in the use of conservative methods for ANFH treatment. We reviewed the studies published in the period from 2010 to 2017. Particular attention was paid to the studies, the results of which were assessed as having evidence levels I and II. Conservative treatment is conventionally represented by three therapeutic types such as medical preparations, biophysical and cell therapies.

Hip joint unloading and natural resolution of the disease

Historically, the earliest treatment for ANFH was unloading of the affected limb using a cane or crutches. It was thought that such therapeutic measures could delay the progression of the disease until the procedures might be performed that preserve the structure of the femoral head. However, in more than $80 \%$ of cases, the disease progresses to collapse of the femur [13]. M.A. Mont et al. [13] conducted a metaanalysis of the results of conservative treatment for ANFH (819 hips) in 1996 and found that the disease progressed in $78 \%$ of patients. At the same time, the amount of joint unloading did not matter, whether it was partial, complete, or not used at all.

In 2010, M.A. Mont et al [14] analyzed the natural history of the disease in 819 patients (664 hips) with asymptomatic ANFH with a mean 7-year follow-up and came to several conclusions. First, the disease progressed to symptomatic ANFH or to femur collapse in $59 \%$ of cases (394 hips). Second, there was a clear correlation between the size of necrosis and its subsequent development. Complaints of pain and limitation of movement were detected in $32 \%$ of patients with small areas of necrosis in the femoral head and in $84 \%$ with extensive lesions. Third, a particularly high risk of progression of the destructive process to the collapse of the femoral head ( $74 \%$ of patients) was observed in patients with sickle cell anemia due to significant changes in the rheological properties of the blood.

Based on the literature data, it may be concluded that the ANFH treatment by unloading the joint is ineffective. However, the issue of using the method in people with increased body weight and severe pain, in whom its use might be justified as an auxiliary means, remained beyond the scope of the discussion.

\section{Medication therapy}

Biphosphonates The bisphosphonate group of agents has a great potential in medication therapy. The mechanism of their action is to inhibit farnesyl pyrophosphatase and enzyme 3-hydroxy-3-methyl-glutaryl-coenzyme A-reductase thus achieving the blocking of the osteoclast resorption process and acceleration of cell apoptosis [15]. One study of level I and two of level IV evidence that evaluated the efficacy of the bisphosphonate alendronate reported excellent joint survival rates (Table 1).

In a level I randomized controlled trial, K.A. Lai et al [16] showed an improvement in joint survival in 28 of $29(93 \%)$ cases, a low rate of transition to total arthroplasty, an increase in the Harris Hip Score by more than 8 points in the group of patients who took alendronate for two years. In the same group, radiography of 29 hips showed progression only in four cases that was significantly different from the results in the control group $(\mathrm{p}<0.001)$.

S. Agarwala and co-authors [17] published the results of alendronate intake for 8 and 10 years (level of evidence IV). The 8-year follow-up showed the efficacy of alendronate as joint survival in 364 from 395 (92 \%) cases, a low rate of subsequent total arthroplasty (31 hips) and absence of progression was confirmed by radiography. Excellent results were reported at the 10-year follow-up but the number of examined persons was smaller [18].

Table 1

Effectiveness of ANFH treatment with bisphosphonates

\begin{tabular}{|c|c|c|c|c|c|}
\hline & \multicolumn{5}{|c|}{ Author, year of publication } \\
\hline & $\begin{array}{l}\text { C.H. Chen et al., } \\
2012\end{array}$ & $\begin{array}{l}\text { K.A. Lai et al., } \\
2005\end{array}$ & $\begin{array}{c}\text { S. Agarwala et al., } \\
2009\end{array}$ & \begin{tabular}{|c|} 
S. Agarwala et al., \\
2011
\end{tabular} & $\begin{array}{l}\text { Y.K. Lee et al., } \\
2015\end{array}$ \\
\hline Agent & \multicolumn{4}{|c|}{ Alendronate } & Zoledronate \\
\hline Hip survival, $\%$ & 88 & 93 & 92 & 87 & 65 \\
\hline Main group, $\mathrm{n}$ & 32 & 29 & 395 & 53 & 55 \\
\hline THA*, main group, $\mathrm{n}$ & 4 & 1 & 31 & 7 & 19 \\
\hline Control group, $\mathrm{n}$ & 33 & 25 & - & - & 55 \\
\hline THA*, control group, $n$ & 5 & 16 & - & - & 20 \\
\hline Treatment duration, months & 24 & 24 & 96 & 120 & 24 \\
\hline Steinberg stage & II-III & II-IIIC & I-III & I-III & I-II \\
\hline Level of evidence & I & I & IV & IV & I \\
\hline
\end{tabular}

* THA - total hip arthroplasty; n-number of hips 
However, a multicentre randomized study of level I reported that four $(12.5 \%)$ out of 32 patients that received alendronate, five (15\%) out of 33 placebo patients had to undergo THA when followed up for two years [19]. Moreover, Y.K. Lee et al [20] showed in their study that there were no significant differences between the group of patients who took zolendronate and the group of patient who did not take the drug in regard to subsequent THA, 19 out of 55 cases and 20 out of 55, respectively. The authors concluded that biophosphonates are ineffective for ANFH treatment.

The controversy of the results in application of the preparations of the biophosphonate group for ANFH treatment might be explained. First, K.A. Lai and coauthors included patients who had core decompression. Second, they evaluated the results only in the radiographs and did not include clinical examination. And third, the sample size was small (fewer than 30 subjects in each group) and did not include the impact of risk factors.

Excellent results of a 10-year study presented by several authors [20] could be explained by inclusion of the patients who would not have ANFH progression even if being untreated with the drugs. Others opine [19] that the divergence in the results could have happened due to differences in the population studied, race origin and due to inclusion into the sample of the individuals with a severer type of necrosis than the rest of the sample.

Thus, the data on the efficacy of the preparations from the group of biphosphonates for ANFH treatment are contraversial, as two eveidence level I studies reported their ineffectiveness while one study of level I and two studies of evidence level IV demonstrated excellent results.

Anticoagulants One of the possible pathogenetic links of primary ANFH is thrombophilia and hypofibrinolysis which lead to impaired venous outflow and an increase in intraosseous pressure [21]. The researchers suggest that systemic anticoagulants may delay the ischemic process by preventing the formation of blood clots. We reviewed data from four studies to evaluate the effectiveness of anticoagulants in primary and secondary ANFH.

According to the results obtained in 2005 by C.J. Glueck [22], 19 of 20 hips (95\%) with primary Ficat I and II ANFN had no radiographic changes within the control period of 2-4 years. When evaluating the efficacy of enoxaparin for secondary ANFH, unsatisfactory results were observed in $80 \%$ of patients (12 out of 15 femurs), as they showed progression of the disease to Ficat IIIIV grade [22]. K. Nagasawa et al [23] also concluded that the use of warfarin to prevent steroid-induced (secondary) ANFH does not achieve a significant effect. In the group of patients receiving warfarin $1-5 \mathrm{mg}$ per day for $3-5$ months, ANFH developed in $21 \%$ of cases (13 of 62 femurs) while in the control group it was $33 \%$ ( 19 of 58 femurs).

In further research in 2015, C.G. Glueck et al [24] came to a different conclusion. They analyzed the results of treatment of 9 femurs (8 Ficat stage II, 1 stage - I) in patients with primary ANFH who received enoxaparin $60 \mathrm{mg}$ per day for 12 weeks. Long-term follow-up data (4 to 16 years), including radiological monitoring, showed that no patient progressed. T. Chotanaphuti et al [25] studied the condition of 15 femurs out of $26(57.7 \%)$ in patients treated with enoxaparin (6,000 U for 12 weeks) and also did not reveal radiographic progression compared with 5 out of 23 femurs ( $21.5 \%$ of cases) in patients who did not receive treatment for 2 years $(\mathrm{p}=0.042)$.

These studies are characterized by small samples and low levels of evidence (two of the studies are uncontrolled). Also, there are no uniform standards for the dose and intake time of anticoagulants; observations differ in duration, therefore, studies are clinically heterogeneous, and their results are not indisputable.

Current publications show that the rate of progression of idiopathic ANFH from pre-collapse to collapse stage was significantly lower in patients receiving this therapy. Therefore, the use of anticoagulants in idiopathic (primary) ANFH in the pre-collapse stage, contrary to the results of earlier studies [23], is justified.

Hypolipidemic drugs Hypolipidemic drugs are indicated in steroid-induced type of ANFH. Glucocorticosteroids cause hyperlipidemia and increase intraosseous pressure resulting in sinusoidal collapse and osteonecrosis [26]. J.W. Pritchett and co-authors [27] reported that on average only $1 \%$ of patients that took high doses of corticosteriods and statins for 7.5 years developed ANFH. Among the patients that took high doses of corticosteroids but without statins, the incidence of ANFH was 3-20\%. However, M. Ajmal et al [28] did not discover a considerable reduction in ANFH incidence either in the patients that received steroids and statins or the patients that used steroids without statins (4.4 against $7 \%$ ).

Despite pathogenic grounds, the use of hypolipidemic means shows insufficient efficacy in the steroidinduced ANFH. At present, no clinical studies with high level of evidence that could prove the effectiveness of hypolipidemic preparations are available.

Vasodilatators Vasodilatators induce blood flow increase in the terminal vessels and stimulate bone regeneration at the cell level. The most common drug used for ANFH treatment is iloprost, a derivative of prostacycline (PGI2), which has an antithrombotic, vasodilatating and antiproliferative effects.

M. Jäger and co-authors [29] analyzed the efficiency of iloprost for treating 95 patients who suffered pain due to elevated intraosseous pressure in the early ANFH stage and stated pain relief and functional improvement. The retrospective study of R. Meizer et al [30] that included 104 patients reported good results as $76 \%$ of patients had pain relief during motion, considerable reduction of bone marrow swelling was observed in $65 \%$ of cases and MRI did not reveal radiographic changes in $20 \%$ of cases.

A.C. Disch and co-authors conducted a study [31] to compare the treatment results in 16 patients with an 
isolated swelling of the femoral head bone marrow and 17 patients with ANFH. The patients of both groups received iloprost for 5 days. Average follow-up was two years (1-3 years). Both groups had an increase in the range of motion $(\mathrm{p}<0.001)$, decrease in pain on VAS scale, reduction in the swelling of bone marrow and reported satisfaction with treatment results.

I. Pountos et al [32] reviewed 27 studies in 2018 and analysed the efficacy of iloprost for treatment of patients with ANFH and bone marrow edema. They concluded that the clinical findings confirm the efficacy of iloporost in the early ANFH and recommended this medical preparation. A. Roth, J. Beckmann et al [33] derived a similar conclusion on the effects of iloprost in the early ANFH stage for pain relief and bone marrow edema in case surgical treatment is contraindicated.

However, along with positive effects of iloprost its side effects should be also mentioned, among which are dyspepsia, headache, insomnia and some others. It is important to know the frequency of such complications and the interaction of the drug with other medical preparations. Thus, the combination of iloprost with anticoagulants has a high risk of bleeding. When combined with antihypertension drugs, iloprost has a potential to increase the hypotensive effect [32]. One more shortcoming of the studies should be noted. The comparisons about the drug effectivenes may be incorrect as the doses used were different. Several authors reported that the reduction in the dose from 50 to $20 \mathrm{mg}$ does not have impact on the therapetic effect [30].

Vasodilatators (prostaglandines) are one of the few groups of preparations with a proven effect in regard to pain arrest or swelling in the early ANFH. Therefore, they may be recommended for symptomatic treatment.

\section{Biophysical methods of treatment}

Hyperbaric oxygenation (HBO) increases extracellular oxygen concentration, reduces cell ischemia, reduces tissue edema, causing vasodilatation. E.M. Camporesi et al [34] studied the effect of hyperbaric oxygenation on the effectiveness of treating femoral head osteonecrosis (level of evidence I). Pain relief was observed after 20 sessions $(p=0.002)$ and 30 sessions $(p<0.001)$ in patients treated with hyperbaric oxygen therapy. None of them underwent arthroplasty. All patients in this group showed a decrease in pain for 7 years. N.D. Reis et al [35] published treatment results of 12 patients with ANFH in stage I, whose treatment included HBO for 100 days. According to MRI data, improvement of the condition of the hip joint was achieved in $81 \%$ of cases.

W. Li and Z. Ye [36] conducted a meta-analysis and review of 9 publications covering 318 cases of $\mathrm{HBO}$ use in comparison with the control group of 305 subjects. The researchers concluded that the clinical efficacy in the group of patients treated with $\mathrm{HBO}$ was 4.95 times higher than in the control group; the difference was statistically significant $(\mathrm{p}<0.00001)$. They also concluded that HBO had a significantly clinical effect in both Asian and non-
Asian population with ANFH. Experiments show [37] that hyperbaric oxygenation and celecoxib are equally effective in relieving pain. But in contrast to celecoxib, HBO does not cause hypersensitization and dyspeptic disorders.

Among the shortcomings of the above studies are small samples of patients, age and population differences, duration of the course of hyperbaric oxygenation; the difference in the total duration of treatment. This dictates the need for research with a higher level of evidence.

In 2016, the X European Consensus Conference on Hyperbaric Medicine was held. It resulted in the conclusion that daily treatment with $\mathrm{HBO}$ for more than 60 minutes 5-6 times a week is recommended for early stages of ANFH (recommendation type 2, level of evidence B) [38]. Hyperbaric oxygenation is not recommended as monotherapy (type of recommendation 1, level of evidence $\mathrm{C}$ ).

The benefits of using hyperbaric oxygenation in the treatment of ANFH have been confirmed in the studies with a high level of evidence, most in Level IV studies. To date, the use of HBO is justified in a complex therapy for ANFH.

According to numerous studies, the use of biophysical therapies such as extracorporeal shock wave therapy (SWT) and pulsed electromagnetic fields also leads to a decrease in pain, improved functional performance, and slower disease progression. It has been assumed that pulsed electromagnetic and shock wave therapy have a beneficial effect by stimulating osteo- and angiogenesis in the early stage of osteonecrosis of the femoral head.

We included five studies of varying levels of evidence that assessed the effectiveness of SWT (Table 2). Thus, in 2001, for the first time, it was suggested [39] that shock wave therapy may be a non-invasive alternative in the treatment of ANFH. The study showed a therapeutic effect in 14 out of 22 patients who underwent shock wave therapy. In 2012 M.C. Vulpani et al [40] conducted a study that included 36 patients with unilateral ANFH, dividing them into groups depending on the stage according to the ARCO classification. They concluded that the use of shock wave therapy in ANFH stage I and II showed better results than in stage III $(p<0.005)$. During two years of follow-up, 10 out of 15 patients with ARCO stage III underwent total arthroplasty, while there was no deterioration according to radiological findings in patients with stages I and II.

Studies by other authors [41] also showed clinical improvement with the use of shock wave therapy. However, the increase in the HHS was mainly due to a decrease in pain and the improvement according to MRI was not statistically significant. Comparison of the effectiveness of shock wave therapy with surgical treatment [42] showed that a good result with shock wave therapy was obtained in $76 \%$ of cases; subsequent arthroplasty was performed in $24 \%$ of patients; in the surgical treatment group, the rates were $21 \%$ and $64 \%$, respectively. SWT was applied in 17 patients with bilateral ANFH after total arthroplasty of one joint in 2009 [43] and showed high clinical effect in 13 of them. 
Table 2

Data on the effectiveness of shockwave therapy in ANFH

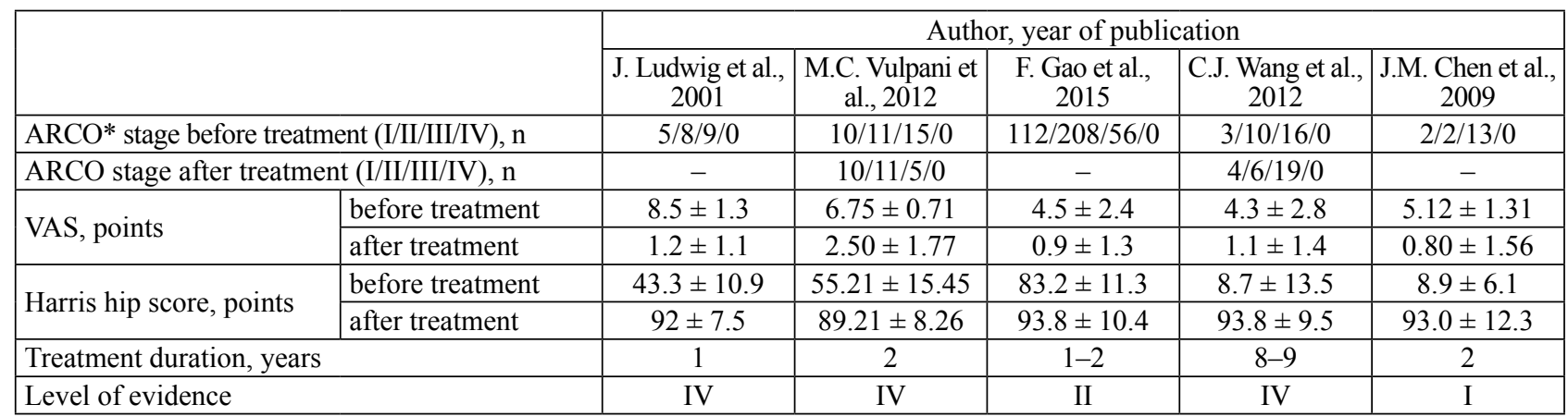

*ARCO - Association Research Circulation Osseous

Radiographic results [44] of treating 51 patients (70 femurs) and the data on hip survival in ANFH patients with ARCO stage I and II after being exposed to the treatment with pulsed electromagnatic fields confirmed the efficacy of $88.57 \%$. Good radiographic and clinical results were reported by other autors . [45] in ANFH Steinberg stage II (81 \%) and III (70 \%). In their earlier work (2006), L. Massari et al [46] also observed high hip survival after treatment with pulsed electromagnatic fields in 76 femurs (80\%).

In 2006, L.D. Neumayr and co-authors [47] published the results of comparing the efficiency of treating patients with sickle cell anemia and associated ANFH. Biophysical methods combined with core decompression were used in one group and only biophysical methods in the control group. Their three-year retrospective study of level II evidence revealed hip survival of $82 \%$ in the main group (18.1 HHS points) while it was $86 \%$ in the control group.

The review of the literature [33] testifies that there is no evidence that shockwave and pulsed electromagnetic field therapy are able to delay THA in cases of ANFH. Although the improvement of the symptoms is possible in the early ANFH, the application of these methods was not recommended.

The combination of pharmacological and biophysical treatments showed ambiguous results. On the one hand, when used combined the shockwave therapy, alendronate and hyperbaric oxygenation resulted in visible improvement in 45 out of 50 cases $(90 \%$ ) [48, 49], the other results [48] revealed the fact that the twoyear outcomes after the combined therapy were similar to monotherapy with application of shockwaves. The same findings were obtained by other authors [49]. This polarity might be explained by heterogeneity of the patient samples and different methods used for treatment result assessment. Moreover, these methods are not available everywhere.

Thus, many clinical study of high evidence level confirm the rationality of shockwave therapy aimed at pain relief and functional hip joint improvement.

\section{Cell therapy}

There has been a great interest to cell therapy applied for locomotor system diseases, including ANFH.

Basing on the fact that one of the causes of osteonecrosis pathogenesis is the lack of the cells that are able to regenerate, the issue of a possible use of cell therapies for bone matrix restoration seems important [50]. The findings of the studies reviewed by us seem promising but showed controversial results. We studied four works of evidence level I [51-54], one was level II [55] and two had level III [56, 57] that showed the analysis of cell therapy effectiveness (Table 3 ).

Based on the analysis of the above works, we came to the conclusion that cell therapy results in clinical improvement and decreased incidence of disease progression. Thus, with the use of mononuclear cells (level of evidence I), restoration of the functions of the hip joint, improvement of metabolic processes in the lesion and pain relief were observed in 85 [52], 92 [53] and $100 \%$ [54] of cases. Mesenchymal stromal cells application showed it in $100 \%$ of cases [51]. In addition, N.S. Piuzzi et al. [58] conducted analysis of the effectiveness of mononuclear cells and found in 9 out of 10 studies a lower incidence of transition to hip arthroplasty in the group of patients who received cell therapy, 62 out of 380 (16\%) cases versus 52 out of $252(21 \%)$ in the control group.

Table 3

Data on the effectiveness of cell therapy in ANFH

\begin{tabular}{|c|c|c|c|c|c|c|c|}
\hline & \multicolumn{7}{|c|}{ Author, year of publication } \\
\hline & \begin{tabular}{|c|} 
D. Zhao et al., \\
2012 \\
\end{tabular} & \begin{tabular}{|c|} 
V. Ganji et al., \\
2011
\end{tabular} & $\begin{array}{c}\text { Y. Ma et al., } \\
2014\end{array}$ & $\begin{array}{c}\text { R.M. Tabatabee } \\
\text { et al., } 2015\end{array}$ & $\begin{array}{c}\text { R.K. Sen et al., } \\
2012\end{array}$ & \begin{tabular}{|c|} 
Y. Liu et al., \\
2013
\end{tabular} & $\begin{array}{c}\text { Rastogi et al., } \\
2013\end{array}$ \\
\hline Therapy & $\begin{array}{c}\text { Bone marrow } \\
\text { cells }\end{array}$ & & & Mononuc & lear cells & & \\
\hline Implant survival, $\%$ & 100 & 85 & 92 & 100 & - & 86 & 100 \\
\hline Number of femurs & 53 & 24 & 59 & 28 & 26 & 55 & 60 \\
\hline Duration of follow-up, months & 60 & 60 & 24 & 24 & 24 & 24 & 24 \\
\hline ARCO stage & I-II & I-II & I-III & I-III & I-II & II & I-III \\
\hline Level of evidence & I & $\mathrm{I}$ & $\mathrm{I}$ & $\mathrm{I}$ & II & III & III \\
\hline
\end{tabular}


The effectiveness of stem cell transplantation remains controversial. Thus, V. Gangji et al. [52], P. Hernigou et al. [50] showed that transplantation of one's own bone marrow cells into the necrosis zone could be effective in the early stages of osteonecrosis. However, Y.W. Lim et al. [59], comparing the clinical and radiological results of stem cell transplantation and bone marrow decompression in 128 patients (190 femurs) with osteonecrosis and the data obtained at 5 -year follow-up, came to less satisfactory results. In the group where stem cells were used, 15 out of $42(35.7 \%)$ patients with ANFH in stage IIa according to Ficat, 16 out of 37 (43.3\%) in stage IIb and 28 out of $49(57.1 \%)$ in stage III required further surgical treatment. And in the group where bone marrow decompression was used, surgical treatment was further required in 5 out of 14 $(35.7 \%)$ patients with ANFH in stage IIa according to Ficat, four out of $9(44.4 \%)$ in stage IIb, five out of 8 $(62.5 \%)$ patients in stage III.

C. Papakostidis et al. [60] conducted a metaanalysis based on a literature review of six publications comparing two patient groups. In the treatment of patients of the first group, a combination of bone decompression and local injection of mesenchymal cells was used, only bone decompression was used in the second group. It was found that in the group of patients receiving cell therapy, the probability of femoral head progression to collapse was five times lower than in the control group $(p=0.02)$. It was also reported about an improvement in functional parameters and a lower incidence of transition to arthroplasty in the main group. The researchers concluded that cell therapy increases joint survival and reduces the need for arthroplasty. However, these findings, given the significant statistical heterogeneity in groups, are not beyond dispute.

Previous studies using bone marrow stem cells have shown satisfactory results. The combination of bone marrow stem cells and PRP-GFC-therapy (one's own platelet-rich blood plasma) may promote the formation of new tissue in bone defects due to growth factors in platelets, significantly improve cartilage regeneration, and therefore the clinical picture. As a result, 45 out of 48 (93\%) patients with ANFH before and after treatment, according to MRI data, had an improved osteogenesis and bone matrix formation. Those patients also showed significant improvement in moto functions, cartilage regeneration (3 to $10 \mathrm{~mm}$ ), and improvement in the quality of life (according to two-year follow-up) [61].

This study and several other studies demonstrate the safety, efficacy and perspectives in cell therapy application; however, studies with a larger number of patients should be conducted.

\section{CONCLUSIONS}

1. The data of the studies of levels of evidence I and II have shown the ineffectiveness of the method of unloading the hip joint and the use of lipid-lowering drugs in the treatment of patients with ANFH.

2. Promising results have been obtained with the use of anticoagulants, vasodilators and cell therapy for ANFH in the pre-collapse stage.

3. Biophysical methods such as hyperbaric oxygenation, extracorporeal shock wave therapy and pulsed electromagnetic fields have been shown to be effective in relieving pain, improving joint function and metabolic processes in the early stages of the disease.

4. The opinions of researchers about the effect of bisphosphonates on the results of treatment of patients with ANFH are controversial. Their efficacy in clinical trials of low level of evidence has not been confirmed by multicenter studies.

\section{REFERENCES}

1. Mustafin R.N., Khusnutdinova E.K. Avaskuliarnyi nekroz golovki bedrennoi kosti [Avascular necrosis of the femoral head]. Vestnik Bashkirskogo GMU, 2016, no. 1, pp. 43-68. (in Russian)

2. Ugnivenko V.I. Razrabotka novykh metodov meditsinskoi reabilitatsii ortopedotravmatologicheskikh bolnykh s tiazhelymi narusheniiami funktsii nizhnikh konechnostei dlia primeneniia $v$ usloviiakh polikliniki: NIR No. 632/056/022. TsITO. Ruk. M.A. Berglezov [Development of new methods for medical rehabilitation of orthopedic-and-traumatological patients with serious disorders of the lower limb function for outpatient use, Scientific Research No 632/056/022. CITO. Berglezov M.A., manager]. M., 2009. (in Russian)

3. Beckmann R., Shaheen H., Kweider N., Ghassemi A., Fragoulis A., Hermanns-Sachweh B., Pufe T., Kadyrov M., Drescher W. Enoxaparin prevents steroid-related avascular necrosis of the femoral head. Scientific World Journal, 2014, vol. 2014, pp. 347813. DOI: 10.1155/2014/347813

4. Wang C., Peng J., Lu S. Summary of the various treatments for osteonecrosis of the femoral head by mechanism: A review. Exp. Ther. Med., 2014, vol. 8, no. 3, pp. 700-706. DOI: 10.3892/etm.2014.1811

5. Babhulkar S. Osteonecrosis of femoral head: Treatment by core decompression and vascular pedicle grafting. Indian J. Orthop., 2009, vol. 43, no. 1, pp. 27-35. DOI: 10.4103/0019-5413.45320

6. Kaushik A.P., Das A., Cui Q. Osteonecrosis of the femoral head: An update in year 2012. World J. Orthop., 2012 , vol. 3, no. 5, pp. 49-57. DOI: $10.5312 /$ wjo.v3.i5.49

7. Assouline-Dayan Y., Chang C., Greenspan A., Shoenfeld Y., Gershwin M.E. Pathogenesis and natural history of osteonecrosis. Semin. Arthritis Rheum., 2002, vol. 32, no. 2, pp. 94-124.

8. Vaidyanathan S., Murugan Y., Paulraj K. An unusual complication in osteonecrosis of femoral head: a case report. Case Rep. Orthop., 2013, vol. 2013, pp. 313289. DOI: 10.1155/2013/313289

9. Li J.M., Li Y., Wang L. The genetic association between PON1 polymorphisms and osteonecrosis of femoral head: A case-control study. Medicine (Baltimore), 2017, vol. 96, no. 42, pp. e8198. DOI: 10.1097/MD.0000000000008198

10. Gong L.L., Fang L.H., Wang H.Y., Peng J.H., Si K., Zhu J., Han F.F., Wang Y.H., Du G.H., Pei L.X., Liu L.H. Genetic risk factors for glucocorticoidinduced osteonecrosis: a meta-analysis. Steroids, 2013, vol. 78, no. 4, pp. 401-408. DOI: 10.1016/j.steroids.2013.01.004 
11. Herrmann M., Tami A., Wildemann B., Wolny M., Wagner A., Schorr H., Taban-Shomal O., Umanskaya N., Ross S., Garcia P., Hübner U., Herrmann W. Hyperhomocysteinemia induces a tissue specific accumulation of homocysteine in bone by collagen binding and adversely affects bone. Bone, 2009, vol. 44, no. 3, pp. 467-475. DOI: 10.1016/j.bone.2008.10.051

12. Holstein J.H., Herrmann M., Splett C., Herrmann W., Garcia P., Histing T., Klein M., Kurz K., Siebel T., Pohlemann T., Menger M.D. High bone concentrations of homocysteine are associated with altered bone morphology in humans. Br. J. Nutr., 2011, vol. 106, no. 3, pp. 378-382. DOI: $10.1017 / S 0007114511000304$

13. Mont M.A., Carbone J.J., Fairbank A.C. Core decompression versus nonoperative management for osteonecrosis of the hip. Clin. Orthop. Relat. Res., 1996, no. 324, pp.169-178. DOI: 10.1097/00003086-199603000-00020

14. Mont M.A., Zywiel M.G., Marker D.R., McGrath M.S., Delanois R.E. The natural history of untreated asymptomatic osteonecrosis of the femoral head: a systematic literature review. J. Bone Joint Surg. Am., 2010, vol. 92, no. 12, pp. 2165-2170. DOI: 10.2106/JBJS.I.00575

15. Kim H.K. Pathophysiology and new strategies or the treatment of Legg-Calvé-Perthes disease. J. Bone Joint Surg. Am., 2012, vol. 94, no. 7, pp. 659669. DOI: $10.2106 / \mathrm{JBJS} . J .01834$

16. Lai K.A., Shen W.J., Yang C.Y., Shao C.J., Hsu J.T., Lin R.M. The use of alendronate to prevent early collapse of the femoral head in patients with nontraumatic osteonecrosis. A randomized clinical study. J. Bone Joint Surg. Am., 2005, vol. 87, no. 10, pp. 2155-2159. DOI: 10.2106/JBJS.D.02959

17. Agarwala S., Shah S., Joshi V.R. The use of alendronate in the treatment of avascular necrosis of the femoral head: follow-up to eight years. J. Bone Joint Surg. Br., 2009, vol. 91, no. 8, pp. 1013-1018. DOI: 10.1302/0301-620X.91B8.21518

18. Agarwala S., Shah S.B. Ten-year follow-up of avascular necrosis of femoral head treated with alendronate for 3 years. J. Arthroplasty, 2011, vol. 26, no. 7, pp. 1128-1134. DOI: 10.1016/j.arth.2010.11.010

19. Chen C.-H., Chang J.-K., Lai K.-A., Hou S.-M., Chang C.-H., Wang G.-J. Alendronate in the prevention of collapse of the femoral head in nontraumatic osteonecrosis: A two-year multicenter, prospective, randomized, double-blind, placebo-controlled study. Arthritis Rheum., 2012, vol. 64 , no. 5, pp.1572-1578. DOI: $10.1002 /$ art.33498

20. Lee Y.K., Ha Y.C., Cho Y.J., Suh K.T., Kim S.Y., Won Y.Y., Min B.W., Yoon T.R., Kim H.J., Koo K.H. Does Zoledronate Prevent Femoral Head Collapse from Osteonecrosis? A Prospective, Randomized, Open-Label, Multicenter Study. J. Bone Joint Surg. Am., 2015, vol. 97, no. 14, pp. 11421148. DOI: 10.2106/JBJS.N.01157

21. Glueck C.J., Freiberg R.A., Wang P. Role of thrombosis in osteonecrosis. Curr. Hematol. Rep., 2003, vol. 2, no. 5, pp. 417-422.

22. Glueck C.J., Freiberg R.A., Sieve L., Wang P. Enoxaparin prevents progression of stages I and II osteonecrosis of the hip. Clin. Orthop. Relat. Res., 2005, no. 435, pp. 164-170. DOI: 10.1097/01.blo.0000157539.67567.03

23. Nagasawa K., Tada Y., Koarada S., Tsukamoto H., Horiuchi T., Yoshizawa S., Murai K., Ueda A., Haruta Y., Ohta A. Prevention of steroidinduced osteonecrosis of femoral head in systemic lupus erythematosus by anti-coagulant. Lupus, 2006, vol. 15, no. 6, pp. 354-357. DOI: $10.1191 / 0961203306 l u 2311$ oa

24. Glueck C.J., Freiberg R.A., Wissman R., Wang P. Long term anticoagulation (4-16 years) stops progression of idiopathic hip osteonecrosis associated with familial thrombophilia. Adv. Orthop., 2015, vol. 2015, pp. 138382. DOI:10.1155/2015/138382

25. Chotanaphuti T., Thongprasert S., Laoruengthana A. Low molecular weight heparin prevents the progression of precollapse osteonecrosis of the hip. J. Med. Assoc. Thai., 2013, vol. 96, no. 10, pp. 1326-1330.

26. Oinuma K., Harada Y., Nawata Y., Takabayashi K., Abe I., Kamikawa K., Moriya H. Sustained hemostatic abnormality in patients with steroid-induced osteonecrosis in the early period after high-dose corticosteroid therapy. J. Orthop. Sci., 2000, vol. 5, no. 4, pp. 374-379. DOI: 10.1007/s007760070046

27. Pritchett J.W. Statin therapy decreases the risk of osteonecrosis in patients receiving steroids. Clin. Orthop. Relat. Res., 2001, no. 386, pp.173-178. DOI: 10.1097/00003086-200105000-00022

28. Ajmal M., Matas A.J., Kuskowski M., Cheng E.Y. Does statin usage reduce the risk of corticosteroid-related osteonecrosis in renal transplant population? Orthop. Clin. North Am., 2009, vol. 40, no. 2, pp. 235-239. DOI: 10.1016/i.ocl.2009.01.004

29. Jäger M., Zilkens C., Bittersohl B., Matheney T., Kozina G., Blondin D., Krauspe R. Efficiency of iloprost treatment for osseous malperfusion. Int. Orthop., 2011, vol. 35, no. 5, pp. 761-765. DOI: 10.1007/s00264-010-0998-4

30. Meizer R., Radda C., Stolz G., Kotsaris S., Petje G., Krasny C., Wlk M., Mayerhöfer M., Landsiedl F., Aigner N. MRI-controlled analysis of 104 patients with painful bone marrow edema in different joint localizations treated with the prostacyclin analogue iloprost. Wien. Klin. Wochenschr., 2005, vol. 117, no. 7-8, pp. 278-286. DOI: $10.1007 / \mathrm{s} 00508-005-0326-\mathrm{y}$

31. Disch A.C., Matziolis G., Perka C. The management of necrosis-associated and idiopathic bone-marrow oedema of the proximal femur by intravenous iloprost. J. Bone Joint Surg. Br., 2005, vol. 87, no. 4, pp. 560-564. DOI: 10.1302/0301-620X.87B4.15658

32. Pountos I., Giannoudis P.V. The role of Iloprost on bone edema and osteonecrosis: Safety and clinical results. Expert Opin. Drug Saf., 2018, vol. 17, no. 3, pp. 225-233, DOI: 10.1080/14740338.2018.1424828

33. Roth A., Beckmann J., Bohndorf K., Fischer A., Heiß C., Kenn W., Jäger M., Maus U., Nöth U., Peters K.M., Rader C., Reppenhagen S., Smolenski U., Tingart M., Kopp I., Sirotin I., Breusch S.J. S3-Guideline non-traumatic adult femoral head necrosis. Arch. Orthop. Trauma Surg., 2016, vol. 136, no. 2, pp. 165-174. DOI: $10.1007 / \mathrm{s} 00402-015-2375-7$

34. Camporesi E.M., Vezzani G., Bosco G., Mangar D., Bernasek T.L. Hyperbaric oxygen therapy in femoral head necrosis. J. Arthroplasty, 2010, vol. 25, no. 6 Suppl., pp. 118-123. DOI: 10.1016/j.arth.2010.05.005

35. Reis N.D., Schwartz O., Militianu D., Ramon Y., Levin D., Norman D., Melamed Y., Shupak A., Goldsher D., Zinman C. Hyperbaric oxygen therapy as a treatment for stage-I avascular necrosis of the femoral head. J. Bone Joint Surg. Br., 2003, vol. 85, no. 3, pp. 371-375. DOI: 10.1302/0301-620x.85b3.13237

36. Li W., Ye Z., Wang W., Wang K., Li L., Zhao D. Clinical effect of hyperbaric oxygen therapy in the treatment of femoral head necrosis: A systematic review and meta-analysis. Orthopade, 2017, vol. 46, no. 5, pp. 440-446. DOI: 10.1007/s00132-016-3360-8

37. Muhonen A., Muhonen J., Lindholm T.C., Minn H., Klossner J., Kulmala J., Happonen R.P. Osteodistraction of a previously irradiated mandible with or without adjunctive hyperbaric oxygenation: an experimental study in rabbits. Int. J. Oral Maxillofac. Surg., 2002, vol. 31, no. 5, pp. 519-524. DOI: 10.1054/ ijom.2002.0257

38. Mathieu D., Marroni A., Kot J. Tenth European Consensus Conference on Hyperbaric Medicine: recommendations for accepted and non-accepted clinical indications and practice of hyperbaric oxygen treatment. Diving Hyperb. Med., 2017, vol. 47, no. 1, pp.24-32. DOI: 10.28920/dhm47.1.24-32

39. Ludwig J., Lauber S., Lauber H.J., Dreisilker U., Raerdel S., Hotzinger H. High-energy shock wave treatment of femoral head necrosis in adults. Clin. Orthop. Relat. Res., 2001, no. 387, pp. 119-126. DOI: 10.1097/00003086-200106000-00016

40. Vulpiani M.C., Vetrano M., Trischitta D., Scarcello L., Chizzi F., Argento G., Saraceni V.M., Maffulli N., Ferretti A. Extracorporeal shock wave therapy in early osteonecrosis of the femoral head: prospective clinical study with long-term follow-up. Arch. Orthop. Trauma Surg., 2012, vol. 132, no. 4, pp. 499508. DOI: $10.1007 / \mathrm{s} 00402-011-1444-9$

41. Gao F., Sun W., Li Z., Guo W., Wang W., Cheng L., Wang B. High-energy extracorporeal shock wave for early stage osteonecrosis of the femoral head: a single-center case series. Evid. Based Complement. Alternat. Med., 2015, vol. 2015, pp. 468090. DOI: 10.1155/2015/468090

42. Wang C.J., Huang C.C. , Wang J.W., Wong T., Yang Y.J. Long-term results of extracorporeal shockwave therapy and core decompression in osteonecrosis of the femoral head with eight- to nine-year follow-up. Biomed. J., 2012, vol. 35, no. 6, pp. 481-485. DOI: 10.4103/2319-4170.104413

43. Chen J.M., Hsu S.L., Wong T., Chou W.Y., Wang C.J., Wang F.S. Functional outcomes of bilateral hip necrosis: total hip arthroplasty versus extracorporeal shockwave. Arch. Orthop. Trauma Surg., 2009, vol. 129, no. 6, pp. 837-841. DOI: 10.1007/s00402-008-0812-6

44. Cebrián J., Milano G., Francés A., Lopiz Y., Marco F., López-Durán L. Role of electromagnetic stimulation in the treatment of osteonecrosis of the femoral head in early stages. J. Biomed. Sci. Eng., 2014, vol. 7, pp. 252-257. DOI: 10.4236/jbise.2014.75028

45. Massari L., Fini M., Cadossi R., Setti S., Traina G. Biophysical stimulation in osteonecrosis of the femoral head. Indian J. Orthop., 2009, vol. 43, no. 1, pp. 17-21. DOI: 10.4103/0019-5413.45319

46. Massari L., Fini M., Cadossi R., Setti S., Traina G.C. Biophysical stimulation with pulsed electromagnetic fields in osteonecrosis of the femoral head. J. Bone Joint Surg. Am., 2006, vol. 88, no. Suppl. 3, pp. 56-60. DOI: 10.2106/JBJS.F.00536 
47. Neumayr L.D., Aguilar C., Earles A.N., Jergesen H.E., Haberkern C.M., Kammen B.F., Nancarrow P.A., Padua E., Milet M., Stulberg B.N., Williams R.A., Orringer E.P., Graber N., Robertson S.M., Vichinsky E.P.; National Osteonecrosis Trial in Sickle Cell Anemia Study Group. Physical therapy alone compared with core decompression and physical therapy for femoral head osteonecrosis in sickle cell disease. Results of a multicenter study at a mean of three years after treatment. J. Bone Joint Surg. Am., 2006, vol. 88, no. 12, pp. 2573-2582. DOI: 10.2106/JBJS.E.01454

48. Hsu S.L., Wang C.J., Lee M.S., Chan Y.S., Huang C.C., Yang K.D. Cocktail therapy for femoral head necrosis of the hip. Arch. Orthop. Trauma Surg., 2010, vol. 130, no. 1, pp. 23-29. DOI: 10.1007/s00402-009-0918-5

49. Wong T., Wang C.J., Hsu S.L., Chou W.Y., Lin P.C., Huang C.C. Cocktail therapy for hip necrosis in SARS patients. Chang Gung Med. J., 2008, vol. 31, no. 6, pp. 546-553.

50. Hernigou P., Flouzat-Lachaniette C.H., Delambre J., Poignard A., Allain J., Chevallier N., Rouard H. Osteonecrosis repair with bone marrow cell therapies: state of the clinical art. Bone, 2015, vol. 70, pp. 102-109. DOI: 10.1016/j.bone.2014.04.034

51. Zhao D., Cui D., Wang B., Tian F., Guo L., Yang L., Liu B., Yu X. Treatment of early stage osteonecrosis of the femoral head with autologous implantation of bone marrow-derived and cultured mesenchymal stem cells. Bone, 2012, vol. 50, no. 1, pp. 325-330. DOI: 10.1016/j.bone.2011.11.002

52. Gangji V., De Maertelaer V., Hauzeur J.P. Autologous bone marrow cell implantation in the treatment of non-traumatic osteonecrosis of the femoral head: Five year follow-up of a prospective controlled study. Bone, 2011, vol. 49, no. 5, pp. 1005-1009. DOI: 10.1016/j.bone.2011.07.032

53. Ma Y., Wang T., Liao J., Gu H., Lin X., Jiang Q., Bulsara M.K., Zheng M., Zheng Q. Efficacy of autologous bone marrow buffy coat grafting combined with core decompression in patients with avascular necrosis of femoral head: a prospective, double-blinded, randomized, controlled study. Stem Cell Res. Ther., 2014, vol. 5, no. 5, pp. 115. DOI: $10.1186 /$ scrt505

54. Tabatabaee R.M., Saberi S., Parvizi J., Mortazavi S.M., Farzan M. Combining Concentrated Autologous Bone Marrow Stem Cells Injection With Core Decompression Improves Outcome for Patients with Early-Stage Osteonecrosis of the Femoral Head: A Comparative Study. J. Arthroplasty, 2015, vol. 30, no. 9 Suppl., pp.11-15. DOI: 10.1016/j.arth.2015.06.022

55. Sen R.K., Tripathy S.K., Aggarwal S., Marwaha N., Sharma R.R., Khandelwal N. Early results of core decompression and autologous bone marrow mononuclear cells instillation in femoral head osteonecrosis: a randomized control study. J. Arthroplasty, 2012, vol. 27, no. 5, pp. 679-686. DOI: 10.1016/j. arth.2011.08.008

56. Liu Y., Liu S., Su X. Core decompression and implantation of bone marrow mononuclear cells with porous hydroxylapatite composite filler for the treatment of osteonecrosis of the femoral head. Arch. Orthop. Trauma Surg., 2013, vol. 133, no. 1, pp. 125-133. DOI: doi: 10.1007/s00402-012-1623-3

57. Rastogi S., Sankineani S.R., Nag H.L., Mohanty S., Shivanand G., Marimuthu K., Kumar R., Rijal L. Intralesional autologous mesenchymal stem cells in management of osteonecrosis of femur: a preliminary study. Musculoskelet. Surg., 2013, vol. 97, no. 3, pp. 223-228. DOI: 10.1007/s12306-013-0273-0

58. Piuzzi N.S., Chahla J., Schrock J.B., LaPrade R.F., Pascual-Garrido C., Mont M.A., Muschler G.F. Evidence for the use of cell-based therapy for the treatment of osteonecrosis of the femoral head: A Systematic Review of the literature. J. Arthroplasty, 2017, vol. 32, no. 5, pp. 1698-1708. DOI: 10.1016/j. arth.2016.12.049

59. Lim Y.W., Kim Y.S., Lee J.W., Kwon S.Y. Stem cell implantation for osteonecrosis of the femoral head. Exp. Mol. Med., 2013 , vol. 45, no. 11, pp. e61. DOI: 10.1038/emm.2013.128

60. Papakostidis C., Tosounidis T.H., Jones E., Giannoudis P.V. The role of «cell therapy» in osteonecrosis of the femoral head. A systematic review of the literature and meta-analysis of 7 studies. Acta Orthop., 2016, vol. 87, no. 1, pp. 72-78. DOI: 10.3109/17453674.2015.1077418

61. Nandeesh N.H., Janardhan K., Subramanian V., Ashtekar A.B., Srikruthi N., Koka P.S., Deb K. Treatment of AVN Using Autologous BM Stem Cells and Activated Platelet-Derived Growth Factor Concentrates. J. Stem Cells, 2016, vol. 11, no. 3, pp. 135-148.

Received: 14.11.2019

\section{Information about the authors:}

1. Vladislav V. Lobashov, M.D.,

Maya-clinic, Kazan, Russian Federation,

Email: lobashoff@ya.ru,

https://orcid.org/0000-0002-3467-0358

2. Airat V. Zainutdinov, M.D.,

Kazan State Medical University, Kazan, Russian Federation,

Email: zainutdinov.airat@yandex.ru,

https://orcid.org/0000-0001-5805-6048

3. Ildar F. Akhtiamov, M.D., Ph.D., Professor,

SAHI City Clinical Hospital № 7, Kazan, Russian Federation,

Kazan State Medical University, Kazan, Russian Federation,

Email: yalta60@mail.ru,

https://orcid.org/0000-0001-5264-5634 